GRASAS Y ACEITES 67 (4)

October-December 2016, e161

ISSN-L: 0017-3495

doi: http://dx.doi.org/10.3989/gya.0451161

\title{
Cardiovascular risk protection from the Mediterranean diet and olive oil. A transcriptomic update in humans*
}

\author{
S. Carrión ${ }^{\mathrm{a}, \mathrm{b}}$, L. Torres ${ }^{\mathrm{a}, \mathrm{c}}$ and O. Castañer ${ }^{\mathrm{a}, \mathrm{d}, \bigotimes}$ \\ ${ }^{a}$ Cardiovascular Risk and Nutrition Research Group (CARIN), Hospital del Mar Medical Research Institute (IMIM). \\ ${ }^{\mathrm{b}}$ Universitat Pompeu Fabra, Barcelona. \\ ${ }^{\mathrm{c}} \mathrm{PhD}$ Program in Food Sciences and Nutrition in Nutrition and Bromatology Department, Faculty of Pharmacy, \\ University of Barcelona, Barcelona, Spain. \\ ${ }^{\mathrm{d}}$ CIBER of the physiopathology of obesity and nutrition (CIBEROBN). \\ ${ }^{\square}$ Corresponding author: ocastaner@imim.es
}

Submitted: 18 April 2016; Accepted: 19 September 2016

SUMMARY: This review highlights the human studies that explore the benefits of the Mediterranean diet and olive oil, based on gene expression analysis. We summarized consistent human transcriptomic studies on cardiovascular risk, based on TMD and olive oil interventions, with real life doses and conditions. A literature review was carried out leading up to February 2016. The results show that the TMD, specially supplemented with virgin olive oil, produces beneficial changes in the transcriptomic response of relevant genes in cardiovascular risk such as CAT, GPX1 and SIRT2. p65 and MCP-1, IL1B, IL6, CXCL1, INF- $\gamma$, ARHGAP15 and IL7R, which are involved in inflammation; and ABCA1, SR-B1, PPARBP, PPAR $\alpha, \operatorname{PPAR} \gamma, \operatorname{PPAR} \delta, \mathrm{CD}-36$ and COX-1, which play an important role in cholesterol efflux. The available data illustrate a transcriptomic effect on atherosclerosis, inflammation and oxidative stress pathways as well as the mentioned genes.

KEYWORDS: Cardiovascular; Mediterranean Diet; MUFA; Nutrigenomics; Olive oil; Polyphenols; Transcriptomics

RESUMEN: Protección cardiovascular de la dieta mediterránea y el aceite de oliva. Una actualización de transcriptómica en humanos. Esta revisión resume los estudios de transcriptómica en humanos que muestran efectos beneficiosos de la dieta mediterránea tradicional (TMD) y el aceite de oliva, en condiciones y dosis de la vida real en relación al riesgo cardiovascular. La revisión se llevó a cabo hasta febrero de 2016. Los resultados muestran que la TMD, especialmente suplementada con aceite de oliva virgen, ejerce cambios beneficiosos en la respuesta transcriptómica de genes relevantes en el riesgo cardiovascular tales como CAT, GPX1 y SIRT2. p65 y MCP-1, IL1B, IL6, CXCL1, INF- $\gamma$, ARHGAP15 y IL7R implicados en la inflamación. ABCA1, SR-B1, PPARBP, PPAR $\alpha, \operatorname{PPAR} \gamma, \operatorname{PPAR} \delta$, CD-36 y la COX-1 juegan un papel importante en el eflujo de colesterol. Además, ADRB2 está relacionada con el estrés oxidativo. Los datos disponibles nos llevan a un efecto transcriptómico sobre las vías de arteriosclerosis, inflamación y estrés oxidativo, así como sobre los genes mencionados.

PALABRAS CLAVE: Aceite de oliva; Ácidos grasos monoinsaturados; Cardiovascular; Dieta mediterránea; Nutrigenómica; Polifenoles; Transcriptómica

Citation/Cómo citar este artículo: Carrión S, Torres L, Castañer O. 2016. Cardiovascular risk protection from the Mediterranean diet and olive oil. A transcriptomic update in humans. Grasas Aceites 67, e161. http://dx.doi. org/10.3989/gya.0451161.

Copyright: (C) 2016 CSIC. This is an open-access article distributed under the terms of the Creative Commons Attribution (CC-by) Spain 3.0 License.

*This manuscript was presented in the I Workshop INSA-UB “The Universe of the Olive Oil”, in November 2015. 


\section{ABBREVIATIONS}

ABCA1, ATP-Binding Cassette transporter1; ADRB2, adrenergic $\beta-2$ receptor; ADRB2, Adrenoceptor Beta 2; ALA, $\alpha$-Linolenic acid; AMI, Acute myocardial infarction; AP-1, Activator protein-1 transcription factor complex; ApoA-1, Apolipoprotein A1; ARHGAP15, Rho GTPase Activating Protein 15; BP, Blood pressure; CAT, catalase; CCL2, Chemokine (C-C motif) ligand 2; CCL5, Chemokine (C-C motif) ligand 5; CD36, Cluster of differentiation 3; CD-36, cluster of differentiation 36; CD40L, Cluster of differentiation 4 antigen ligand; CHD, Coronary heart disease; CHD, Carbohydrate; COX-1; Cyclooxygenase1;CVD, Cardiovascular disease; CXCL1, Chemokine (C-X-C motif) ligand 1; EFSA, European Food Safety Authority; EMR1, EGF-like module containing mucin-like hormone receptor; eNOS, endothelial nitric oxide synthase; EPA, Eicosapentaenoic acid; ET-1, Endothelin-1; EUROLIVE, European Study of the Antioxidant Effects of Olive Oil and its Phenolic Compounds on lipid oxidation; FDA, U.S. Food and Drug Administration; GPX1, Glutathione peroxidase 1; GSH/GSSG ratio, Reduced glutathione/oxidized gluthatione; GSR, Glutathione Reductase, GSTP1, Glutathione S-transferase P; GWAS, Genome-wide association study; HDL, high density lipoproteins; IFN- $\gamma$, Interferon gamma; IL1B, Interleukin-1 beta; IL23A, InterleukinL$23 \alpha$ subunit p19; IL-6, Interleukine 6; IL7R, Interleukin 7 receptor alpha chain; IL8RA, Interleukin-8 receptor- $\alpha$; LDL, low density lipoproteins; LPL, lipoprotein lipase; LRP1, lipoprotein receptor-related protein 1; MAPKs, Mitogen-activated protein kinases; MCP-1, Monocyte chemoattractant protein-1; MedDiet, Mediterranean Diet; mRNA, messenger RNA; MUFA, Monounsaturated fatty acids; NADPH, Reduced Nicotinamide adenine dinucleotide phosphate; NAFLD, Non-alcoholic fatty liver disease; NF-Kb, Transcription factor kappaB; NO, nitric oxide; NRF2, Nuclear factor (erythroid-derived 2)-like 2; OLR1, oxidized LDL (lectin-like) receptor 1; OO, olive oil; OxLDL, Oxidized LDL; PBMCs, Peripheral blood mononuclear cells; PCR, Polymerase chain reaction; PPARBP, peroxisome proliferator-activated receptor binding protein; PPARs, Peroxisome proliferator-activated receptors; PPAR $\alpha$, peroxisome proliferator-activated receptor alfa; $\operatorname{PPAR} \gamma$, peroxisome proliferator-activated receptor betta; PPAR $\delta$, peroxisome proliferatoractivated receptor gamma;PPL, Postprandial triglyceridemia; PREDIMED, Prevención con
Dieta Mediterranea; PUFA, Polyunsaturated fatty acids; qRT-PCR, quantitative real timePCR; ROS, Reactive oxygen species; SBP, Systolic blood pressure; SFA, Saturated fatty acids; SIRT2, NAD-dependent deacetylase sirtuin-2 ;SNPs, Single nucleotide polymorphisms; SOD1, Superoxide dismutase 1; SOP, Sulphate of potash; SOX, Dimethylpolysiloxane; SR-B1, Scavenger receptor class B member 1; TFPI, Tissue factor pathway inhibitor; TMD, Traditional Mediterranean Diet; TNF- $\alpha$, Tumor necrosis factor alpha; VOO, Virgin Olive Oil.

\section{INTRODUCTION}

\subsection{The Mediterranean Diet}

The Traditional Mediterranean Diet (TMD) has been historically associated with good health. In 2010, UNESCO officially defined the TMD as an intangible cultural heritage of humanity, sensory stimulation, socialization, biodiversity, and seasonality, aspects that can reinforce the TMD's beneficial effects on wellbeing, quality of life, and health (Bach-Faig et al., 2011; UNESCO). It is specifically from countries surrounding the Mediterranean basin. The pyramid representation graphically highlights the food groups to be consumed since 1995, when this healthy pattern was made popular worldwide (Willett et al., 1995). The TMD is characterized by a high intake of vegetables, fruits, cereals, legumes, and nuts; a moderate to high intake of fish and poultry, low red meat intake, small dairy products consumption, and moderate wine consumption with meals (Willett et al., 1995). Despite all the variants of the TMD, they all share one food component: Olive oil, considered the hallmark of this dietary pattern. Olive oil is a natural olive juice and its major components are fatty acids: MUFA (55-83\%), polyunsaturated fatty acids (PUFA) (4-20\%) and saturated fatty acids (SFA) (8-14\%) (Tripoli et al., 2005). The soluble fraction containing the minor olive oil components, such as the phenolic compounds constitutes $1-2 \%$ of the total content (Owen et al., 2000). In November 2004, the U.S. Food and Drug Administration (FDA) assessed a health claim regarding olive oil and coronary heart disease (CHD) risk reduction benefits, suggesting that "eating about 2 tablespoons (23 grams) of olive oil daily could reduce the risk of CHD due to the monounsaturated fat (MUFA) in olive oil" according to US Food and Drug Administration (2004). Later, scientific evidence demonstrated that the health effects could also be attributed to the olive oil's phenolic fraction 
(Granados-Principal et al., 2010) and, consequently, the European Food Safety Authority (EFSA) released a claim concerning the benefits of a daily ingestion of olive oil rich in phenolic compounds, such as VOO. It is considered that at least $5 \mathrm{mg}$ of hydroxytirosol per $20 \mathrm{~g}$ of olive oil should be consumed daily in order to support the claim (EFSA Journal, 2011).

\subsection{Cardiovascular disease and diet}

Cardiovascular disease (CVD) represents a worldwide burden. Around 17.5 million people die each year from CVDs (31\% of all deaths) and it seems to be rising substantially, due to population growth and increased longevity (World Health Organization, 2011).

There are several cardiovascular risk factors that interact synergistically. Some of these factors are preventable, like tobacco use, physical inactivity and unhealthy diet. These modifiable behaviors are responsible for about $80 \%$ of CVD (World Health Organization, 2011). The results from randomized primary and secondary prevention clinical trials support the relevance of modifying dietary habits. Low fruit and vegetable consumption produce $2,8 \%$ approximately of deaths worldwide (World Health Organization, 2011) while their adequate consumption reduces the risk of CVD (Schröder et al., 2007). It has also been evidenced that while saturated fat and trans-fat (mainly of animal origin), increase the risk of coronary heart disease (CHD), the replacement with monounsaturated and polyunsaturated fat reduces the risk (Estruch et al., 2013).

According to these facts, it was postulated that a TMD intervention reduces cardiovascular events (acute myocardial infarction, stroke and cardiovascular mortality) in individuals at high cardiovascular risk (Estruch et al., 1995) and reduces recurrences in secondary prevention (Lorgeril et al., 1999), as has been demonstrated in clinical trials "in vivo".

Recently, the PREDIMED (Prevención con Dieta Mediterranea) study, a primary prevention trial, showed that an unrestricted-energy Mediterranean diet, supplemented with extra-virgin olive oil or nuts, reduced the incidence of major cardiovascular events by $30 \%$ in people at high cardiovascular risk (Estruch et al., 2013). Similarly, the Lyon Diet Heart Study, a secondary prevention trial, showed a $47 \%$ reduction in rates of CHD events with a modified Mediterranean diet enriched with alpha-linoleic acid, a key constituent of walnuts (Lorgeril et al., 1999).

\subsection{The Mediterranean diet's effect on oxidation and inflammation processes}

Atherosclerosis, defined as the loss of plasticity and narrowing of the arterial lumen as a consequence of atherosclerotic plaque development, is the main pathophysiological factor related to CVD. A number of highly interrelated processes result in atherosclerosis; the study of all these processes has led to the consideration of new emergent risk factors for CVD and novel biomarkers to manage this disease. Among these processes, oxidation and inflammation play a key role according to Berliner (Berliner et al., 1995).

The phenolic compounds in olive oil have proven antioxidant and anti-inflammatory properties, as well as an improvement in endothelial function and the lipid profile (Owen et al., 2000; Zern and Fernandez, 2005; Visioli et al., 2000).

The European Study of the Antioxidant Effects of Olive Oil and its Phenolic Compounds on lipid oxidation (EUROLIVE) study (Covas et al., 2006) was a clinical trial to evaluate the effects of the phenolic content in olive oil on the plasma lipid profile and lipid oxidative damage. The systemic markers of lipid oxidation decreased inversely with the phenolic content of the olive oil (particularly low density lipoprotein (LDL) oxidation markers) and high density lipoprotein (HDL) cholesterol levels increased in a direct relationship with the phenolic content of the olive oil. This increase in HDL cholesterol and the decrease of oxidized LDL (oxLDL) in a dose dependent manner with the phenolic content of the olive oil, pointed out an independent effect of the phenolic compounds in olive oil (OO) beyond the effect of oleic acid. These results indicated that not only monounsaturated fatty acids but also the phenolic fraction of the olive oil had an impact on the lipid profile and oxidative damage to lipids. This clinical trial was one of the key reports to provide evidence to recommend polyphenol-rich olive oil as a source of fat to achieve additional benefits against CVD risk factors.

OxLDL is a key factor in the atherosclerosis process. The oxidation of LDL is a pre-requisite for macrophage action in the subendothelial space (uptake and cellular accumulation of cholesterol) one of the prior steps to the formation of the fatty streak. Higher serum concentrations of oxLDL have been observed in acute myocardial infarction (AMI) patients versus controls (Tsimikas et al., 2005) and a predictive value has been attributed to oxLDL in the general population (Meisinger et al., 2005; Gómez et al., 2009).

Nowadays studies focused on HDL report that HDL lipoproteins' functional capacities are more 
relevant than the mere HDL cholesterol quantity. Olive oil polyphenols seem to promote these capacities, like the cholesterol efflux capacity, improving HDL antioxidant and inflammatory capacity (Hernáez et al., 2016).

\subsection{Nutrigenomics}

Omic technologies give us a holistic view, with integrated information about the molecules that make up a cell, tissue or organism (Fito and Konstantinidou, 2016). We can distinguish between:

1) Genomics: the systematic study of an organism's genome (structure, function, and expression); 2) Transcriptomics: The transcriptome is the total messenger-RNA (mRNA) in a cell or organism and the template for protein synthesis in a process called translation. The transcriptome reflects the genes that are actively expressed at any given moment. Gene expression microarrays measure packaged mRNA as a summary of gene activity; 3 ) Proteomics aims to characterize the information flow within the cell and the organism, through protein pathways and networks, with the eventual aim of understanding the functional relevance of proteins; 4) Metabolomics: The metabolome is the final downstream product of gene transcription, therefore, changes in the metabolome are amplified relative to changes in the transcriptome and the proteome (Horgan and Kenny., 2011).

Nutrients and food components have an effect on the whole-body physiology and health status at a molecular and cellular level. Molecular nutrition research has great potential since it can promote health and lower mortality and morbidity by determining the molecular mechanisms that underlay this processes.

The DNA microarrays are used to measure the DNA sequence or expression differences among individuals. It has the capacity to analyze the expression of thousands of genes simultaneously by measuring the changes in mRNA abundance. In gene expression analysis, RNA is extracted from the samples (normal/control and disease/case samples you want to compare), translated to cDNA by a reverse transcription process, labeled (addition of fluorescent dyes) and hybridized with the microarray slide. The cDNA undergoes an amplification process by polymerase chain reaction (PCR) and is positioned into the solid support of the array (the microarray glass sides or chips). There is an ultraviolet laser that scans the slide and is able to detect the amount of fluorescent signals for each gene, which will depend on the expression in each sample. The image is then analyzed to determine which gene expressions are significantly different. These changes should be then validated in all the samples studied using real-time PCR (Horgan and Kenny, 2011).

The majority of studies assessing differential expression directly undergo real time PCR. In this case the genes or pathways analyzed will be the ones selected on the basis of a set on genes reported to be significant for the studied process or detected to be differentially expressed in previous microarray analyses. The real time polymerase chain reaction will allow the amplification of all the DNA introduced and its simultaneous quantification (Bustin, 2000). It is also applied in cDNA reversal transcribed from RNA extracted from samples that we want to compare (Konstantinidou et al., 2013).

Clinical intervention trials are a good approach for conducting gene-nutrient phenotype association studies and the combination of high-throughput technologies are clarifying the mechanisms by which TMD exerts its beneficial effects on human health.

Our aim was to summarize consistent human nutrigenomic studies related to the TMD and olive oil intake in a high cardiovascular risk population.

\section{MATERIALS AND METHODS}

\subsection{Literature review}

A literature review was carried out in PUBMED. We searched for randomized controlled clinical trials assessing the effect of acute or sustained intervention with the TMD or OO consumption on the human gene expression related to oxidation/ inflammation-related processes in cardiovascular risk. The following MESH terms were submitted: (mediterranean diet [TitlelAbstract] OR olive oil [TitlelAbstract]) AND (gene expression [Titlel Abstract] OR transcriptomic* [TitlelAbstract] OR nutrigenomic* [TitlelAbstract]). Studies performed in cellular or animal models were excluded; as well as those related to cancer or other conditions that differ from the ones of our interest. Studies lacking control and/or were not randomized and those in which external solutions were used as a supplementation (drugs, pills, antioxidants mix, etc.) were also excluded. Table 1 summarizes the main transcriptomic findings obtained in these 16 selected studies, as well as the study and intervention design, the evaluated constituent and the studied outcome and other facts. We have up-dated and summarized the available knowledge in the field of nutrigenomics and Mediterranean diet and olive oil intake on cardiovascular risk.

\section{RESULTS}

\subsection{Study design and methodology}

The TMD as a whole dietary pattern has an impact on cardiovascular risk prevention and several studies have reported the effects of this diet at a molecular level.

The studies are based on the nutrigenomic analysis of different constituents of the TMD; the type of 


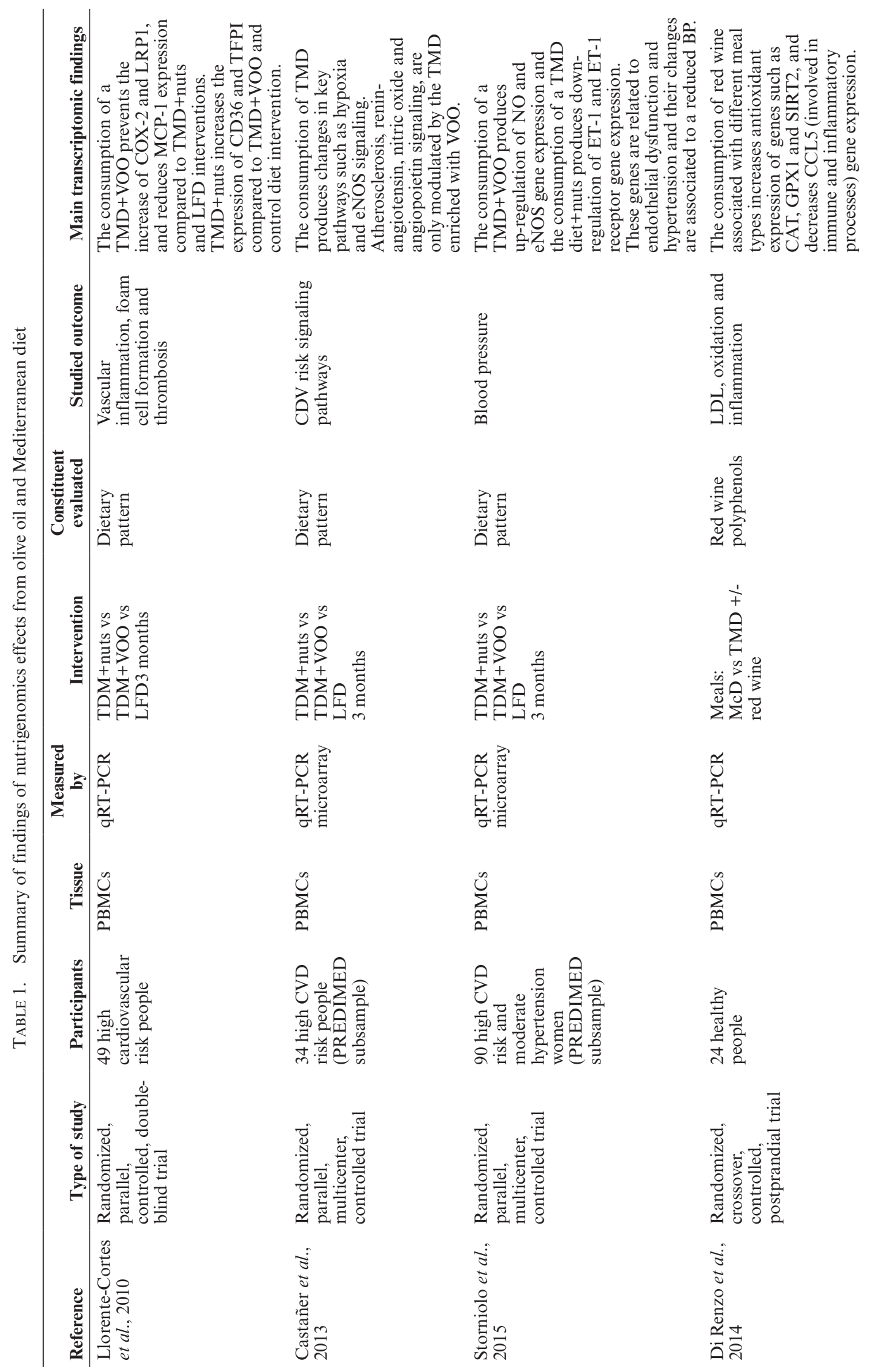




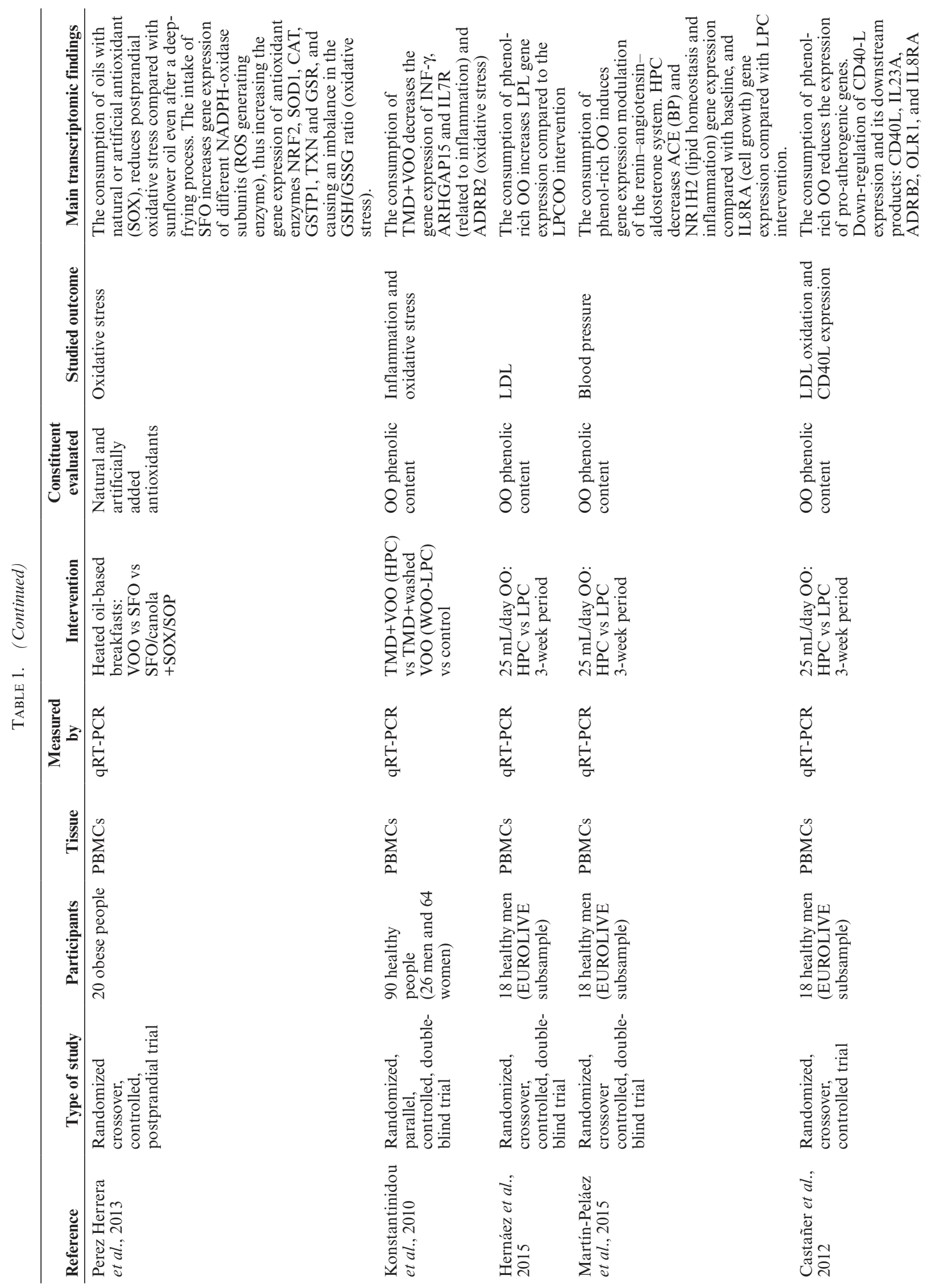




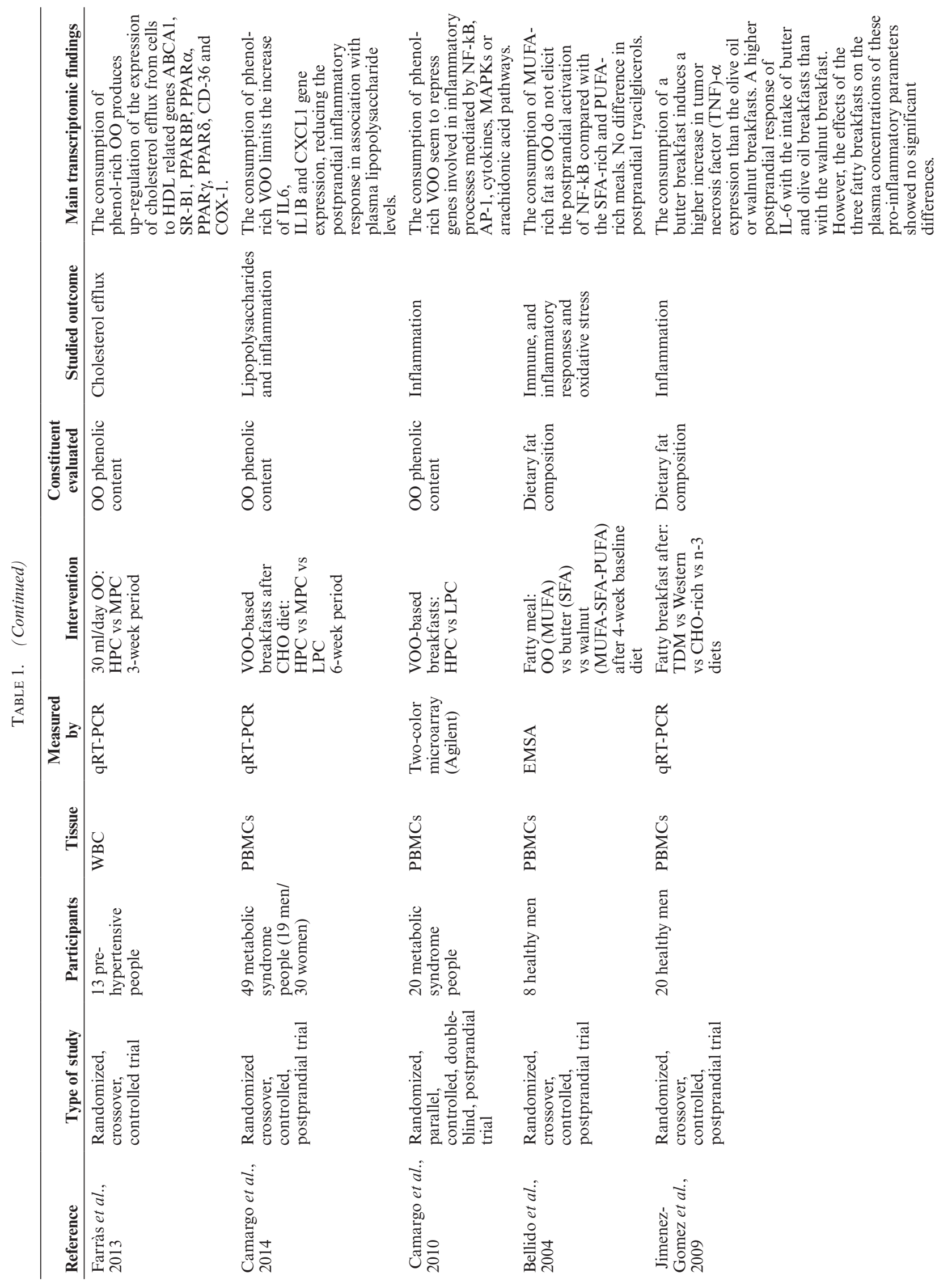




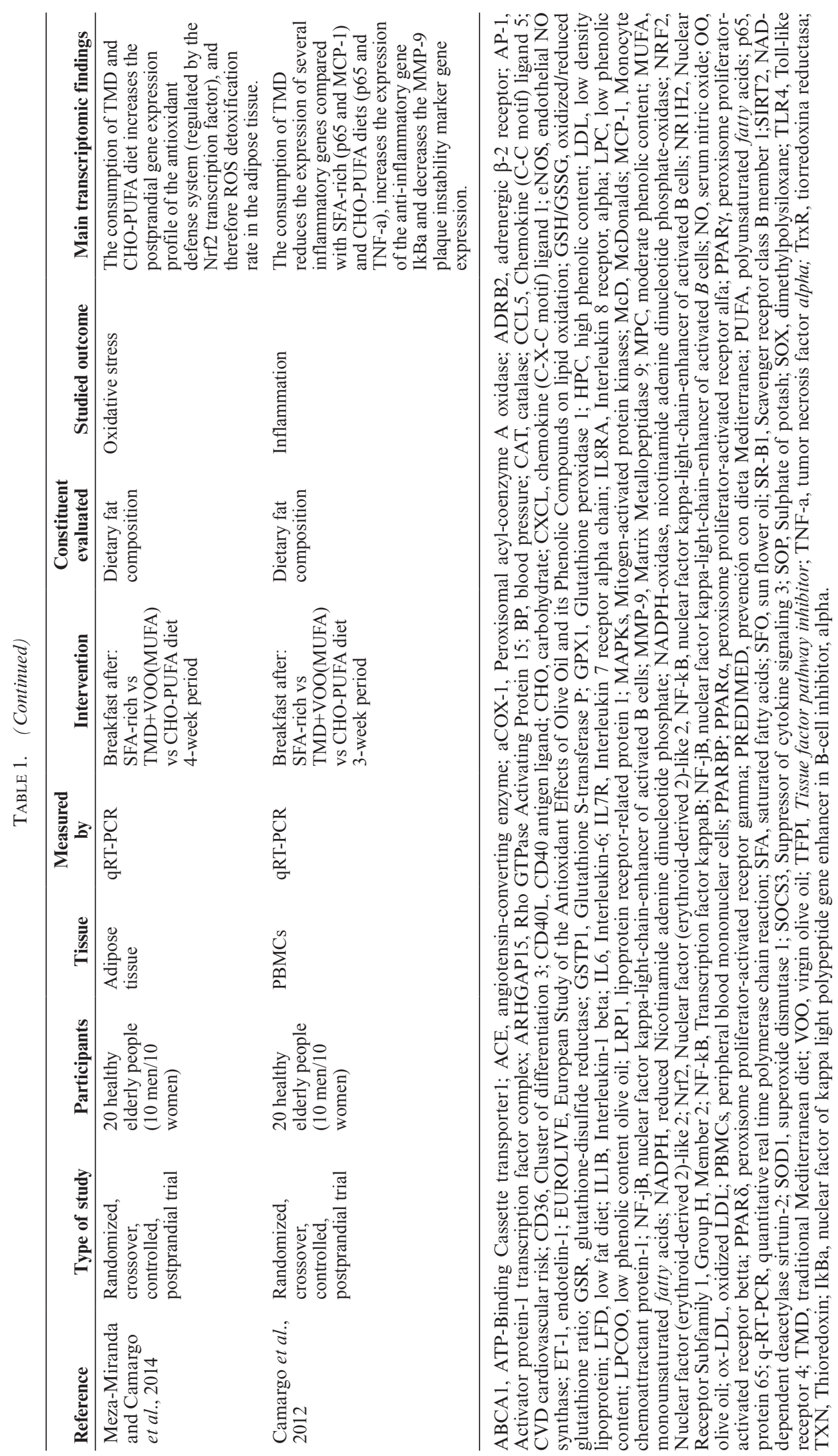


OO antioxidants, the OO phenolic content, the type of dietary fat (MUFA, SFA, carbohydrate-PUFA (CHO-PUFA)), and the polyphenols of red wine. Their aim is to unravel the transcriptional molecular effects of these nutrients on the underlying mechanisms of processes like ageing, inflammation, oxidative stress, CD40Ligand expression, blood pressure control, lipoprotein lipase (LPL) expression, cholesterol efflux, LDL oxidation and inflammation, among others.

Gene expression is always measured by quantitative real time-PCR (qRT-PCR) and the analyzed genes are those known to be relevant for specific pathways related to cardiovascular diseases or selected after a microarray. The inaccessibility of human tissues is an important challenge in human transcriptomic studies. Blood, subcutaneous adipose tissue, and skeletal muscle are among the tissues that can be collected relatively easily. The reviewed studies, however, are usually carried out in peripheral blood mononuclear cells (PBMCs) because they have been reported as useful cardiovascular markers and their collection is viable for population-based studies. The trials also concur on the bases of the design, giving strength to the conclusions; randomized controlled trials can provide first-level scientific evidence. Multicenter trials and real-life conditions are encouraged to fully provide evidence for recommendations to the population. Double-blind conditions add robustness to the design but were not always possible. Other differences among them are the parallel/crossover design and the postprandial/ fasting sample obtainment.

The summary of findings is shown in Table 1.

\subsection{Prevention through the Mediterranean diet. Nutrigenomic findings}

Despite the high prevalence of CVD risk factors observed in Mediterranean countries, there is a low incidence of CVD, which can be attributed to some protective factors related to lifestyle, such as the high degree of adherence to the Mediterranean diet (Jousilahti et al., 1995; Strazzullo et al., 1986). Although the relevance of these associations is high, the potential interactions of different nutrients with lifestyle happening among the general population must be also considered. However, most studies are observational, and consequently establishing causal inference is hindered by residual confounding factors. Thus, large-scale randomized nutritional trials and follow-up cohorts are needed to provide a higher level of scientific evidence.

Being overweight is an important risk factor for CVD but the TMD, without being a low fat diet, is reported to be a healthy diet and to improve the CVD risk (Estruch et al., 2013). Hypertension is also a common chronic health problem and it increases the risk for cardiovascular events and renal failure
(Casas-Agustench et al., 2011). The TMD and its connected lifestyle are also associated with low blood pressure (BP) (Strazzullo et al., 1986; CasasAgustench et al., 2011).

The PREDIMED Study was a large, parallelgroup, multicenter, randomized, and controlled trial to assess the diet effects in the primary prevention of CVD and intermediate biomarkers, among them nutrigenomic changes. Participants at high cardiovascular risk were randomly assigned to the control low-fat diet group or to the traditional Mediterranean diet (TMD) + Virgin Olive Oil (VOO) or TMD+nuts intervention groups in equal proportions (Estruch et al., 2013).

Llorente-Cortes et al., 2010 studied the transcriptomic effect of the TMD on pro-atherotrombotic genes in a PREDIMED sub-sample of 49 high-cardiovascular risk people. Their results suggested, on one hand, that a TMD with VOO complementation prevents the increase in the expression of inflammatory genes (such as Cyclooxygenase1 (COX-1) and Low density lipoprotein receptor-related protein 1(LRP1)) and reduces the expression of antiinflammatory ones like Monocyte chemoattractant protein-1 (MCP-1), compared with a low-fat diet and with a TMD complemented with nuts. This nut complementation, on the other hand, increased the expression of anti-thrombotic genes, such as Tissue factor pathway inhibitor (TFPI) and anti-foam cell formation such as CD36.

Castañer et al., 2013 analyzed the transcriptomic profile of a subsample of 34 PREDIMED participants in which three month changes in PBMC were assessed. Functional annotation analysis was performed on responder genes selected to study cardiovascular canonical pathways after whole transcriptome microarray analyses. $43 \%$ of the 18 cardiovascular canonical pathways were modulated by both TMDs, the most prevalent related to atherosclerosis and hypertension. Key pathways such as hypoxia and endothelial nitric oxide synthase (eNOS) signaling where modulated by both TMDs whereas others, like atherosclerosis, renin-angiotensin, nitric oxide and angiopoietin signaling, were only modulated my the TMD+VOO. In addition, systolic blood pressure (SBP) decreased significantly after the TMD+VOO intervention.

Nitric oxide (NO) is a relaxing factor whereas endothelin-1 (ET-1) is a vasoconstrictor peptide. Both have an important role in the maintenance of vascular homeostasis and their changes are associated with a reduced BP. Storniolo et al., 2015 studied a subsample of 90 PREDIMED participants to assess diet-induced transcriptomic changes in blood pressure control elements such as nitric oxide (NO), ET-1 and ET-1 receptors, involved in endothelial dysfunction and hypertension in order to demonstrate their correlation. They concluded that the consumption of a TMD+VOO produces up-regulation 
of NO and eNOS gene expression and the consumption of a TMD+nuts produces down-regulation of ET-1 and ET-1 receptor gene expression.

These results indicate that the TMD, specially supplemented with virgin olive oil can exert changes in the transcriptomic response of genes related to cardiovascular risk, exerting health benefits, even in a high-risk population.

\subsection{Antioxidant and anti-inflammatory properties of the Mediterranean diet components: polyphenols}

The TMD is reported to have beneficial effects on oxidative and inflammatory conditions but the particular contribution of each one of the components of the TMD separately is being studied; for example, virgin olive oil is known to have antioxidant and anti-inflammatory properties. Other studies have centered their attention on determining the antioxidant and anti-inflammatory properties of the polyphenols of other components of the TMD, such as red wine, in gene expression terms.

Di Renzo et al., 2014 conducted a crossover postprandial trial in which 24 healthy people consumed MacDonald's or TMD based meals with or without red wine in order to assess the anti-oxidant and anti-inflammatory properties of the red wine polyphenols and the differences observed in the context of different meals. The consumption of red wine increased the antioxidant expression of genes such as catalase (CAT), Glutathione peroxidase 1 (GPX1) and NAD-dependent deacetylase sirtuin-2 (SIRT2), and decreased the expression of some immune and inflammatory process-related genes such as Chemokine (C-C motif) ligand 5 (CCL5), independently of the meal type consumed. While CAT encodes a catalase that protects cells from the toxic effects of hydrogen peroxide such as cell or tissue damage, GPX1 encodes a member of the glutathione peroxidase family that protects the hemoglobin in erythrocytes from oxidative breakdown. SIRT2 encodes a member of the sirtuin family of proteins but its biological function and mechanism of action in inflammation and oxidative stress is not fully understood. Finally, CCL5 is a chemotactic cytokine which plays diverse roles in the pathology of inflammatory disease. One of its duties consists of regulating the trafficking of Th1 T cells.

Perez Herrera et al., 2013 focused their research on the antioxidant properties of different oils heated at frying temperatures with or without antioxidant phenolic compounds (natural or artificially added antioxidants). They conducted a crossover postprandial trial in which 20 obese people received 4 breakfasts consisting of different oils (VOO, sunflower oil (SFO) and SFO/canola oil + dimethylpolysiloxane (SOX) (artificial antioxidant) or Sulphate of potash (SOP) (natural antioxidants from olives) which were subjected to 20 heating cycles. The consumption of oils with natural or artificial antioxidants reduced postprandial oxidative stress while the intake of SFO increased the gene expression of the different reduced Nicotinamide adenine dinucleotide phosphate (NADPH)-oxidase subunits (Reactive oxygen species (ROS) generating enzyme), thus increasing the gene expression of antioxidant enzymes Nuclear factor (erythroid-derived 2)-like 2 (NRF2), superoxide dismutase 1 (SOD1), CAT, Glutathione S-transferase P (GSTP1), Thioredoxin (TXN) and Glutathione Reductase (GSR), and causing an imbalance in the reduced glutathione/ oxidized gluthatione (GSH/GSSG ratio).

These results support the fact that different components of the TMD, like red wine, have antioxidant and anti-inflammatory properties. In addition, the oils with phenolic compounds, whether natural (VOO) or artificially added or with artificial antioxidants, could reduce postprandial oxidative stress.

\subsection{Long term nutrigenomic effects of the polyphenols of olive oil}

Olive oil, as said, is the hallmark of the Mediterranean diet and its main source of fat.

Depending on factors such as the olive variety, the age of the tree, agricultural techniques used in cultivation, climate and processing technique, among others, the content of the phenolic composition of olive oil varies in quantity (50-800 $\mathrm{mg} / \mathrm{L}$ ). Virgin olive oil (VOO) is produced by direct pressing or centrifugation of the olives under conditions that do not alter the product. It is rich in phenolic compounds (around 150-400 ppm) and has low acidity $(2.0 \mathrm{~g} / 100 \mathrm{~g}$ maximum in European Union standards). Different processing methods or refining processes produce other olive oils such as ordinary or pomace olive oil in which some components, mainly phenolic compounds, are lost (Willet et al., 1995).

Konstantinidou et al., 2010 also assessed the effect of high and low-phenolic content OO (washed virgin olive oil) on inflammation and oxidative stress. In this case, olive oils were consumed in the context of a TMD in a parallel clinical trial for 3 months by 90 healthy people. TMD and VOO resulted in a decreased expression of genes related to inflammation (such as Interferon gamma (IFN- $\gamma$ ), Rho GTPase Activating Protein 15 (ARHGAP15) and Interleukin 7 receptor alpha chain (IL7R)) and oxidative stress such as Adrenoceptor Beta 2 (ADRB2).

These results were in agreement with previous ones concerning the fact that the benefits associated with polyphenol-rich olive oil consumption in cardiovascular risk could be mediated through an in vivo nutrigenomic effect in humans.

The EUROLIVE study was a multicenter, randomized, crossover trial designed to assess the effect 
on lipids and lipid oxidative damage in a healthy population of sustained doses of oil differing in the phenolic compound content. Participants were randomly assigned to 3-week intervention periods of $25 \mathrm{ml} /$ day of raw oil administration with high, moderate or low phenolic contents.

Hernáez et al., 2015, Martín-Pelaez et al., 2015 and Castañer et al., 2012 analyzed gene expression changes in 18 EUROLIVE subsample male participants in order to study the relation between LPL, blood pressure and CD40L gene expression respectively and the phenolic compound contents of oil intake. They concluded, respectively, that phenolic compound-rich $\mathrm{OO}$ a) increases LPLgene expression, b) increases angiotensin-converting enzyme (ACE), Nuclear Receptor Subfamily 1, Group H, Member 2 (NRH1H2) and, Interleukin 8 receptor alpha (IL8RA) gene expression and c) decreases pro-atherogenic genes, CD40L and its downstream product gene expression: CD40L, Interleukin$23 \alpha$ subunit p19 (IL23A), adrenergic $\beta-2$ receptor (ADRB2), oxidized LDL (lectin-like) receptor 1 (OLR1), and Interleukin-8 receptor- $\alpha$ (IL8RA). These findings provide evidence that phenol-rich olive oil provides cardiovascular health benefits through molecular mechanisms. LPL catalyzes the hydrolysis of triglycerides to release free fatty acids into circulation, raising HDL, lowering LDL concentrations and improving oxidative status. The modulation of genes related with the homeostasis and inflammation of the renin-angiotensin-aldosterone system could underlie the observed decrease in systolic blood pressure. CD40L and related genes are involved in atherogenic and inflammatory processes. Farras et al., 2013, followed a similar methodology to assess the expression of genes related to cholesterol efflux depending on the phenolic content of the olive oil. The crossover trial consisted of the administration of $30 \mathrm{~mL} /$ day of high and moderate polyphenol content oil during 3-week periods to 13 pre/hypertensive people. The results indicate that the intake of phenol-rich OO produces an upregulation of the expression peripheral blood mononuclear cells of genes related to cholesterol efflux from cells (ATP-Binding Cassette transporter1 (ABCA1), Scavenger receptor class B member 1 (SR-B1), PPAR binding protein (PPARBP), peroxisome proliferator-activated receptor alfa (PPAR $\alpha)$, peroxisome proliferator-activated receptor betta (PPAR $\gamma$ ), peroxisome proliferator-activated receptor gamma (PPAR $\delta$ ), cluster of differentiation 36 (CD-36) and COX-1. ABCA1 and SR-B1 are the main transmembrane transporters for cholesterol efflux. The peroxisome proliferator-activated receptors (PPARs) are the nuclear receptor factor family involved in regulating reverse cholesterol transportrelated genes. PPARBP is a co-activator of PPAR $\alpha$ and PPAR $\gamma$, which have been reported to decrease CD40, MCP1 and other inflammatory-related responses. PPAR $\delta$ seems to be related to an increase in HDL cholesterol. PPAR $\gamma$ up-regulates CD-36, a scavenger receptor that promotes the uptake of oxLDL and this, in turn, increases monocyte CD36 expression (Farras et al., 2013).

Reverse cholesterol transport is crucial to prevent the development of atherosclerosis plaque when an accumulation of cholesterol in macrophages occurs. This accumulated cholesterol is collected by HDL and Apolipoprotein A1 (ApoA-1) through several mechanisms. HDL oxidation reduces HDL functionality by impairing cholesterol efflux from macrophages. Polyphenols have been shown to protect HDL and LDL from oxidation and modulate the expression of inflammation-related genes towards a protective mode.

These results support those of the EUROLIVE and demonstrate that olive oil polyphenols are able to modulate transduction and cell signaling through gene expression changes in key pathways, apart from scavenging free radicals. These protection effects are dose-dependent.

\subsection{Postprandial inflammatory response to the polyphenols of olive oil in the context of different diets}

The human being spends most of the time in a postprandial state so it is essential to know what changes are produced during the postprandial phase and how this is influenced by the quality and quantity of the ingested fat. That is the main reason why a lot of studies take their samples in a postprandial state.

In order to investigate the molecular mechanisms by which phenolic compounds in olive oil reduce the postprandial inflammatory response, some studies were based on transcriptomic analyses in the context of different dietary patterns.

Camargo et al., 2014, conducted a crossover postprandial trial consisting of the consumption of different phenol contents in virgin olive oilbased breakfasts (high, moderate and low) after a carbohydrate rich (CHO) diet for 6 weeks in 49 participants with metabolic syndrome. They concluded that some genes such as Interleukin-6 (IL6), Interleukin-1 beta (IL1B) and chemokine (C-X-C motif) ligand 1 (CXCL1) were down-regulated, implying a reduction in the postprandial inflammatory response.

Camargo et al., 2010, also conducted another parallel, postprandial trial in 20 metabolic syndrome people, assessing the effect of different polyphenol content olive oils (high content vs low content and control). In this case, they performed a microarray analysis in which they identified differentially expressed genes between the groups, indicating that high-phenolic content VOO is associated to an antiinflammatory process through the gene expression repression mediated by the transcription factor 
kappaB (NF-Kb), activator protein-1 transcription factor complex (AP-1), cytokines, mitogen-activated protein kinases (MAPKs) or arachidonic acid pathways. Many of the genes involved in these pathways are also relevant in other alterations such as the lipid profile, type 2 diabetes mellitus and obesity.

Other studies assessed the postprandial inflammatory response after the consumption of diets differing in their fat content.

A number of studies have shown that unsaturated fat (MUFA and PUFA) have beneficial effects on blood lipids and the inflammatory state. It has been reported that their consumption can improve the lipid profile; a MUFA-rich diet was able to reduce total and LDL cholesterol in moderately obese humans and a n-6 PUFA-enriched diet produced a decrease in postprandial triacylglycerol compared with SFA-rich butter (Gardner and Kraemer, 2011; Bos et al., 2010; Masson and Mensink, 2011). The replacement of SFA with cis-MUFA improved the total/HDL cholesterol ratio and if the replacement was made with n-6 PUFA, postprandial tumor necrosis factor alpha (TNF- $\alpha$ ) and interleukine 6 (IL-6) plasma levels were reduced in obese men (Egert et al., 2009). In northern Europe it is difficult to recommend high amounts of OO intake, so fat replacement with rapeseed oil has been tested. Rapeseed oil (RO) contains a high quantity of MUFA, almost as much as OO but more PUFA, (especially $\alpha$-Linolenic acid (ALA) and 6-linoleic acid) (Kratz et al., 2002). Supplementation with ALA is reported to reduce fasting serum triglycerides in normo-lipidemic humans (Egert et al., 2009).

Obese individuals with low-grade inflammation have an increased risk of developing nonalcoholic fatty liver disease and, in this process IL-6 release from adipose tissue can induce hepatic insulin resistance. Previous knowledge indicates that dietary fat composition modulation may improve nonalcoholic fatty liver disease, n-6 PUFA from RO reduces fat liver content and Eicosapentaenoic acid (EPA) prevents Non-alcoholic fatty liver disease (NAFLD) (Smith and Adams, 2011). Kruse et al., 2015, studied the influence and postprandial inflammatory response of a daily nutritional supplementation of MUFA and PUFA in moderately obese men comparing a $50 \mathrm{~g}$ supplementation diet of $\mathrm{OO}$ vs RO. This addition caused an increase in the fat consumed in both groups and the overall daily diet was isocaloric in order to not confound the effects of weight change with the oil supplementation. In the RO group, there was a postprandial gene expression increase of IL1B and IL6 (pro-inflammatory cytoquines), Chemokine (C-C motif) ligand 2 (CCL2) and EGF-like module containing a mucin-like hormone receptor (EMR1) which increases macrophage invasion in adipose tissue; and of CCL2 in the OO group; all of them are known up-regulated markers in the chronic inflammation occurring in obesity.
They also observed a reduced long-term IL6 gene expression after RO consumption. These results indicate that RO consumption in nonalcoholic fatty liver disease reduces serum enzymes and has a beneficial postprandial inflammation response.

Pietraszek et al., 2014, assessed the effects of monounsaturated fat on postprandial lipemia and gene expression in first-degree relatives of subjects with type 2 diabetes. Their conclusions were that a MUFA-rich meal elicits similar postprandial triglyceridemia, insulin and incretin responses in type 2 diabetes relatives and the control group, but has a differential impact on gene expression pointing to early defects in lipid metabolismin type 2 diabetes relatives.

All these results suggest that dietary fat content modulates postprandial inflammatory response and provokes a differential gene expression. Moreover, personal genotypes or conditions such as obesity can also be differentially modulated by the fat consumed.

In the following section we present other examples of reviewed trials, which are based on a fatty breakfast after a certain diet.

Bellido et al., 2004 studied the effect of the intake of meals with three different fat composition on the postprandial activation of NF-kB, which results in immune and inflammatory gene responses. They conducted a crossover postprandial trial in which 8 healthy men consumed an OO-based meal differing in fat composition (MUFA, SFA and MUFA-SFAPUFA rich) after 4 weeks of washout consisting of a baseline diet. Their results suggest that NF-kB activation could be one of the reasons for the cardioprotective effect observed by MUFA-rich fat intake such as OO. Jimenez-Gomez et al., 2009, conducted a similar crossover postprandial clinical trial in which 20 healthy men were also tested for their transcriptomic response related to inflammation after a fatty breakfast intake in participants that had followed three different types of diets: SFA (Western), TMD+VOO (MUFA), CHO-rich and n-3 rich diets. The gene expression of TNF-alpha was higher after breakfast in the group that had consumed the SFA diet while the IL-6 expression was lower in the group that followed the PUFA diet. Both genes are involved in inflammation processes and their transcriptomic changes might underlie cardio-protective effects due to the intake of VOO and nuts.

Meza-Miranda et al., 2014, and Camargo et al., 2012 , conducted a crossover postprandial trial in 20 healthy elderly people who followed three diets for 3 -week periods each. The diets differed in the fat type; SFA-rich, TMD+VOO (MUFA) and CHOPUFA. After a breakfast with a similar composition to the final dietary period, samples of adipose tissue and blood (PBMCs) where taken in order to assess the nutrigenomic changes related to oxidative stress and inflammatory response, depending on 
the dietary fat administered. Meza-Miranda et al., 2014 and Camargo et al., 2012, showed an increase in the postprandial gene expression profile of the antioxidant defense system due to the consumption of TMD and CHO-PUFA diet compared with the SFA-rich diet. Camargo et al., 2012 observed that TMD (MUFA) consumption reduces the expression of several inflammatory genes compared to SFArich (p65 and MCP-1) and CHO-PUFA diets (p65 and TNF-a), increases the expression of the antiinflammatory gene IkBa and decreases the MMP-9 plaque instability marker gene expression.

All these results suggested that the in vivo postprandial response happening after a meal can be regulated by the dietary fat intake; and that TMD, rich in MUFA, provides protection against oxidative stress and inflammation.

\section{LIMITATIONS}

All the studies selected for the review have robust designs, but the subsamples chosen for the transcriptomic analysis and the periods provided are still small to fully guarantee the results, although they have improved with time.

The main limitation of all these studies is the potential interaction between the components in the study and others in the diet that might affect the generalization of the results. When studying the effects after TMD consumption due to MUFA content, it could be possible that they are due to minor components in olive oil or a combination of both. When studding the differences among phenol content intake it is possible that the phenol intake comes from other diet components aside from the olive oil.

\section{FUTURE}

Confirmation of the results in different and larger populations, longer intervention periods and evaluation of the gene expression changes in human tissues, other than PBMCs, are still needed.

The future of high-throughput techniques with new and more accessible capacities for nutrigenomics, as well as the advance in the study of the proteome and the metabolome will lead to the integrated systems biology that will allow for a better and more complete understanding of the global changes in the cell and the organism. That information will provide the understanding of the molecular mechanisms underlying the transcriptomic changes which are still not clear in many cases. These approaches will allow for the detection of new biomarkers of interest and the advance towards protective cardiovascular medicine through diet and even to personalized genomic advice.

Genome-wide association studies (GWAS) are a very useful technique in the determination of single nucleotide polymorphisms (SNPs) and genomic variations which can predispose disease. The integration with transcriptome information can reveal the effect of diet modulation on certain genotypes. In depth cardiovascular research with these methods will be very useful.

\section{CONCLUSIONS}

16 clinical trials in humans assessing the nutrigenomic effects of the Mediterranean diet or some of its components on cardiovascular risk or related processes have been analyzed. There are differences among study designs and lack of end-point homogeneity as the outcomes and constituents evaluated are different, but the methodology is similar, in general qRT-PCR in reported or selected by microarray genes from PBMCs has been used.

The Mediterranean diet is a healthy diet that can exert changes in the transcriptomic response of genes related to cardiovascular risk, especially supplemented with virgin olive oil. Atherosclerosis, hypertension and blood pressure are some of the most relevant pathways modulated with diet and the health benefits turn out to be more beneficial than those from a low-fat diet. The consumption of the TMD and VOO produces up-regulation of NO and eNOS gene expression and TMD and nuts down-regulate ET-1 and ET-1 receptor gene expression. These genes are involved in endothelial dysfunction and hypertension and their changes are associated with low BP (Storniolo et al., 2015).

The TMD plays an important role in key pathways such as hypoxia and eNOS signaling. In addition, it increases the postprandial gene expression profile of the antioxidant defense system and therefore, the ROS detoxification rate in adipose tissue. The TMD reduces the expression of several inflammation genes such as p65 and MCP-1 compared with SFA-rich and CHO-PUFA diets (p65 and TNF- $\alpha$ ) and increases the expression of the antiinflammatory gene IkBa and decreases the MMP-9 plaque instability marker gene expression (Camargo et al., 2012).

Among the TMD components, polyphenols have anti-inflammatory and antioxidant properties. The consumption of red wine, for example, increases the antioxidant expression of genes such as CAT, GPX1 and SIRT2, while it decreases some immune and inflammatory process-related gene expression such as CCL5. Oils with phenolic compounds, natural (VOO) or artificially added and even after heated at frying temperature, are able to reduce postprandial oxidative stress while the consumption of polyphenols and antioxidant-lacking oils like sunflower produce the inverse effect.

The properties of polyphenols are dose-dependent and the high content polyphenol oils are the healthiest. 
Phenol-rich olive oil produces cardiovascular health benefits, lowering its risk factors, through molecular mechanisms modulating cell signaling gene expression pathways, apart from the effects of the scavenging of free radicals. Some of these transcriptional modulations are the increase in LPL (hydrolysis of triglycerides to release free fatty acids into circulation, HDL cholesterol rise, lower LDL concentrations and improvement in oxidative status), which reduces the inflammation and oxidative stress. ACE, NRH1H2 and IL8RA expression are modulated by phenol rich $\mathrm{OO}$ and these genes are involved in homeostasis and inflammation of the renin-angiotensin-aldosterone system. The consumption of phenol-rich $\mathrm{OO}$ also up-regulates the expression of cholesterol efflux from cells to HDL related genes such as ABCA1, SR-B1, PPARBP, PPAR $\alpha, \operatorname{PPAR} \gamma, \operatorname{PPAR} \delta, \mathrm{CD}-36$ and COX-1. Equally important, it reduces the expression of pro-atherogenic genes, down-regulating CD40L expression and its downstream products related to atherogenic and inflammatory processes. Fat type and content in oils and diets also modulates postprandial inflammatory response and gene expression. MUFA-rich diets, such as TMD, provide protection from oxidative stress and inflammation. Their consumption reduces the gene expression of several inflammatory (such as p65, MCP 1 and TNF) and plaque instability genes and increases the expression of anti-inflammatory genes.

IL1B, IL6, CXCL1, INF- $\gamma$, ARHGAP15 and IL7R are genes related to postprandial inflammatory response and ADRB2 is related to oxidative stress whose expression is decreased by the consumption of TMD and VOO. In addition, the transcription factor NF-Kb mediates different inflammatory pathways that involve several genes that are differentially expressed depending on the phenol-content intake, underlying the high relevance of the diet in inflammatory processes.

Processes that lead to a rise in chronic inflammation and oxidative stress, such as cardiovascular, neurodegenerative diseases, and aging could be treated and/or prevented through dietary intervention.

The Mediterranean diet with its richness in polyphenols and MUFA components induces transcriptomic gene expression variations that trigger healthy and cardio-protective effects.

\section{ACKNOWLEDGEMENTS}

Joan Rodés Contract (JR14/00008). CIBEROBN is an initiative of Health Institute Carlos III.

\section{REFERENCES}

Bach-Faig A, Berry EM, Lairon D, Reguant J, Trichopoulou A, Dernini S. 2011. Mediterranean diet pyramid today. Science and cultural updates. Public Health Nutr. 14, 2274 2284. http://dx.doi.org/10.1017/S1368980011002515
Bellido C, López-Miranda J, Blanco-Colio LM, Pérez-Martínez P, Muriana FJ, Martín-Ventura JL. 2004. Butter and walnuts, but not olive oil, elicit postprandial activation of nuclear transcription factor kappaB in peripheral blood mononuclear cells from healthy men. Am. J. Clin. Nutr. 80,1487-1491.

Berliner JA, Navab M, Fogelman AM, Frank JS, Demer LL, Edwards PA. 1995. Atherosclerosis: basic mechanisms. Oxidation, inflammation, and genetics. Circulation 91, 2488-2496.

Bos MB, de Vries JHM, Feskens EJM, van Dijk SJ, Hoelen DWM, Siebelink E. 2010. Effect of a high monounsaturated fatty acids diet and a Mediterranean diet on serum lipids and insulin sensitivity in adults with mild abdominal obesity. Nutr. Metab. Cardiovasc. Dis. 20, 591-598. http:// dx.doi.org/10.1016/j.numecd.2009.05.008

Bustin SA. 2000. Absolute quantification of mRNA using real-time reverse transcription polymerase chain reaction assays. J. Mol. Endocrinol. 25, 169-193.

Camargo A, Delgado-Lista J, Garcia-Rios A, Cruz-Teno C, Yubero-Serrano EM, Perez-Martinez P. 2012. Expression of proinflammatory, proatherogenic genes is reduced by the Mediterranean diet in elderly people. Br. J. Nutr. 108 , 500-508. http://dx.doi.org/10.1017/S0007114511005812

Camargo A, Rangel-Zuñiga OA, Haro C, Meza-Miranda ER, Peña-Orihuela $\mathrm{P}$, Meneses ME. 2014. Olive oil phenolic compounds decrease the postprandial inflammatory response by reducing postprandial plasma lipopolysaccharide levels. Food Chem. 162, 161-171. http://dx.doi. org/10.1016/j.foodchem.2014.04.047

Camargo A, Ruano J, Fernandez JM, Parnell LD, Jimenez A, Santos-Gonzalez M. 2010. Gene expression changes in mononuclear cells in patients with metabolic syndrome after acute intake of phenol-rich virgin olive oil. BMC Genomics 11, 253. http://dx.doi. org/10.1186/1471-2164-11-253

Casas-Agustench P, López-Uriarte P, Ros E, Bulló M, SalasSalvadó J. 2011. Nuts, hypertension and endothelial function. Nutr. Metab. Cardiovasc. Dis. 21, S21-S33. http:// dx.doi.org/10.1016/i.numecd.2011.01.009

Castañer O, Corella D, Covas M-I, Sorlí JV, Subirana I, FloresMateo G. 2013. In vivo transcriptomic profile after a Mediterranean diet in high-cardiovascular risk patients: a randomized controlled trial. Am. J. Clin. Nutr. 98, 845-53. http://dx.doi.org/10.3945/ajcn.113.060582

Castañer O, Covas M-I, Khymenets O, Nyyssonen K, Konstantinidou V, Zunft H-F. 2012. Protection of LDL from oxidation by olive oil polyphenols is associated with a downregulation of CD40-ligand expression and its downstream products in vivo in humans. Am. J. Clin. Nutr. 95, 1238-1244. http://dx.doi.org/10.3945/ajcn.111.029207

Covas M-I, Nyyssönen K, Poulsen HE, Kaikkonen J, Zunft H-JF, Kiesewetter H. 2006. The effect of polyphenols in olive oil on heart disease risk factors: a randomized trial. Ann. Intern. Med. 145, 333-341.

Di Renzo L, Carraro A, Valente R, Iacopino L, Colica C, De Lorenzo A. 2014. Intake of red wine in different meals modulates oxidized LDL level, oxidative and inflammatory gene expression in healthy people: a randomized crossover trial. Oxid. Med. Cell Longev. 2014:681318. http://dx.doi. org/10.1155/2014/681318

EFSA Journal. 2011.9, 2033-2058. doi:10.2903/j.efsa.2011.2033. Available online: www.efsa.europa.eu/efsajournal

Egert S, Kannenberg F, Somoza V, Erbersdobler HF, Wahrburg U. 2009. Dietary alpha-linolenic acid, EPA, and DHA have differential effects on LDL fatty acid composition but similar effects on serum lipid profiles in normolipidemic humans. J. Nutr. 139, 861-868. http://dx.doi.org/10.3945/ jn.108.103861

Estruch R, Ros E, Salas-Salvadó J, Covas M, Corella D, Arós F, Gómez-Gracia E, Ruiz-Gutiérrez V, Fiol Sala M, Lapetra J, Lamuela Raventós RM, Serra Majem L, Pintó Sala X, Basora-Gallisá J, Muñoz MÁ, Sorlí JV, Martínez JA, Martínez-González MÁ. 2013. Primary prevention of cardiovascular disease with Mediterranean diet. 
N. Engl. J. Med.365, 1279-1290. http://dx.doi.org/10.1056/ NEJMoa1200303

Farràs M, Valls RM, Fernández-Castillejo S, Giralt M, Solà R, Subirana I, Motilva MJ, Konstantinidou V, Covas MI, Fitó M. 2013. Olive oil polyphenols enhance the expression of cholesterol efflux related genes in vivo in humans. A randomized controlled trial. J. Nutr. Biochem. 24, 1334 1339. http://dx.doi.org/10.1016/j.jnutbio.2012.10.008

Fitó M, Konstantinidou V. 2016. Nutritional Genomics and the Mediterranean Diet's Effects on Human Cardiovascular Health. Nutrients 8, 218. http://dx.doi.org/10.3390/ nu8040218

Gardner CD, Kraemer HC. 1995. Monounsaturated versus polyunsaturated dietary fat and serum lipids. A metaanalysis. Arterioscler. Thromb. Vasc. Biol. 15, 1917-1927.

Gómez M, Valle V, Arós F, Sanz G, Sala J, Fiol M. 2009. Oxidized LDL, lipoprotein (a) and other emergent risk factors in acute myocardial infarction (FORTIAM study). Rev. Esp. Cardiol. 62, 373-382.

Granados-Principal S, Quiles JL, Ramirez-Tortosa CL, Sanchez-Rovira P, Ramirez-Tortosa MC. 2010. Hydroxytyrosol: from laboratory investigations to future clinical trials. Nutr. Rev. 68, 191-206. http://dx.doi. org/10.1111/j.1753-4887.2010.00278.x

Hernáez A, Farràs M, Fitó M. 2016. Olive oil phenolic compounds and high-density lipoprotein function. Curr. Opin. Lipidol. 27, 47-53. http://dx.doi.org/10.1097/ MOL.0000000000000261

Hernáez Á, Remaley AT, Farràs M, Fernández-Castillejo S, Subirana I, Schröder H, Fernández-Mampel M, MuñozAguayo D, Sampson M, Solà R, Farré M, de la Torre R, López-Sabater MC, Nyyssönen K, Zunft H-JF, Covas MI, Fitó M. 2015. Olive Oil Polyphenols Decrease LDL Concentrations and LDL Atherogenicity in Men in a Randomized Controlled Trial. J. Nutr. 145, 1692-7. http:// dx.doi.org/10.3945/jn.115.211557

Horgan RP, Kenny LC. 2011. "Omic" technologies: genomics, transcriptomics, proteomics and metabolomics. Obstet. Gynaecol. 13, 189-195. http://dx.doi.org/10.1576/ toag.13.3.189.27672

Intangible Heritage Home - intangible heritage - Culture Sector UNESCO [Internet]. [cited $2016 \mathrm{Apr} 7$ ]. Available from: http://www.unesco.org/culture/ich/index.php

Jiménez-Gómez Y, López-Miranda J, Blanco-Colio LM, Marín C, Pérez-Martínez P, Ruano J, Paniagua JA, Rodríguez F, Egido J, Pérez-Jiménez F. 2009. Olive oil and walnut breakfasts reduce the postprandial inflammatory response in mononuclear cells compared with a butter breakfast in healthy men. Atherosclerosis 204, e70-e76. http://dx.doi. org/10.1016/j.atherosclerosis.2008.09.011

Jousilahti P, Tuomilehto J, Vartiainen E, Korhonen HJ, Pitkaniemi J, Nissinen A, 1995. Importance of Risk Factor Clustering in Coronary Heart Disease Mortality and Incidence in Eastern Finland. Eur. J. Cardiovasc. Prev. Rehabil. 2, 63-70.

Konstantinidou V, Covas MI, Muñoz-Aguayo D, Khymenets O, de la Torre R, Saez G, Tormos MC, Toledo E, Marti A, Ruiz-Gutiérrez V, Ruiz Mendez MV, Fito M. 2010. In vivo nutrigenomic effects of virgin olive oil polyphenols within the frame of the Mediterranean diet: a randomized controlled trial. FASEB J. 24, 2546-2557. http://dx.doi. org/10.1096/fj.09-148452

Konstantinidou V, Covas MI, Sola R, Fito M. 2013. Up-to date knowledge on the in vivo transcriptomic effect of the Mediterranean diet in humans. Mol. Nutr. Food Res. 57, 772-783. http://dx.doi.org/10.1002/mnfr.201200613

Kratz M, Gülbahçe E, von Eckardstein A, Cullen P, Cignarella A, Assmann G, Wahrburg U. 2002. Dietary mono- and polyunsaturated fatty acids similarly affect LDL size in healthy men and women. J. Nutr. 132, 715-718.

Kruse M, von Loeffelholz C, Hoffmann D, Pohlmann A, Seltmann A-C, Osterhoff M, Hornemann S, Pivovarova O, Rohn S, Jahreis G, Pfeiffer AFH. 2015. Dietary rapeseed/ canola-oil supplementation reduces serum lipids and liver enzymes and alters postprandial inflammatory responses in adipose tissue compared to olive-oil supplementation in obese men. Mol. Nutr. Food Res. 59, 507-519. http:// dx.doi.org/10.1002/mnfr.201400446

Llorente-Cortés V, Estruch R, Mena MP, Ros E, González MAM, Fitó M, Lamuela-Raventós RM, Badimon L. 2010, Effect of Mediterranean diet on the expression of pro-atherogenic genes in a population at high cardiovascular risk. Atherosclerosis 208, 442-450. http://dx.doi. org/10.1016/j.atherosclerosis.2009.08.004

Lorgeril M, Salen P, Martin JL, Monjaud I, Delaye J, Mamelle N. 1999. Mediterranean diet, traditional risk factors, and the rate of cardiovascular complications after myocardial infarction: final report of the Lyon Diet Heart Study. Circulation 99, 779-85.

Martín-Peláez S, Castañer O, Konstantinidou V, Subirana I, Muñoz-Aguayo D, Blanchart G, Gaixas S, de la Torre $\mathrm{R}$, Farré M, Sáez GT, Nyyssönen Kr, Joachim Zunft $\mathrm{H}$, Covas MI, Fitó M. 2015. Effect of olive oil phenolic compounds on the expression of blood pressure-related genes in healthy individuals. Eur. J. Nutr. 1-8. http://dx.doi. org/10.1007/s00394-015-1110-z

Masson CJ, Mensink RP. 2011. Exchanging saturated fatty acids for (n-6) polyunsaturated fatty acids in a mixed meal may decrease postprandial lipemia and markers of inflammation and endothelial activity in overweight men. J. Nutr. 141, 816-821. http://dx.doi.org/10.3945/ jn. 110.136432

Meisinger C, Baumert J, Khuseyinova N, Loewel H, Koenig W. 2005. Plasma oxidized low-density lipoprotein, a strong predictor for acute coronary heart disease events in apparently healthy, middle-aged men from the general population. Circulation 112, 651-657. http://dx.doi.org/10.1161/ CIRCULATIONAHA.104.529297

Meza-Miranda ER, Camargo A, Rangel-Zuñiga OA, Delgado-Lista J, Garcia-Rios A, Perez-Martinez P. 2014. Postprandial oxidative stress is modulated by dietary fat in adipose tissue from elderly people. Age (Dordr) 36, $507-$ 517. http://dx.doi.org/10.1007/s11357-013-9579-y

Owen RW, Mier W, Giacosa A, Hull WE, Spiegelhalder B, Bartsch H. 2000. Phenolic compounds and squalene in olive oils: the concentration and antioxidant potential of total phenols, simple phenols, secoiridoids, lignansand squalene. Food Chem. Toxicol. 38, 647-59.

Perez-Herrera A, Rangel-Zuñiga OA, Delgado-Lista J, Marin C, Perez-Martinez P, Tasset I, 2013. The antioxidants in oils heated at frying temperature, whether natural or added, could protect against postprandial oxidative stress in obese people. Food Chem. 138, 2250-2259. http://dx.doi. org/10.1016/j.foodchem.2012.12.023

Pietraszek A, Gregersen S, Pedersen SB, Holst JJ, Hermansen K. 2014. Acute effects of monounsaturated fat on postprandial lipemia and gene expression in first-degree relatives of subjects with type 2 diabetes. Eur. J. Clin. Nutr. 68, 1022-1028. http://dx.doi.org/10.1038/ejen.2014.64

Schröder H, Elosua R, Vila J, Marti H, Covas MI, Marrugat J. 2007. Secular trends of obesity and cardiovascular risk factors in a Mediterranean population. Obesity (Silver Spring) 15, 557-562. http///dx doi.org/10.1038/oby 2007.574

Smith BW, Adams LA. Non-alcoholic fatty liver disease. 2011. Crit. Rev. Clin. Lab. Sci. 48, 97-113. http://dx.doi.org/10. 3109/10408363.2011.596521

Storniolo CE, Casillas R, Bulló M, Castañer O, Ros E, Sáez GT, Toledo E, Estruch R, Ruiz-Gutiérrez V, Fitó M, Martínez-González MA, Salas-Salvadó J, Mitjavila MT, Moreno JJ. 2015. A Mediterranean diet supplemented with extra virgin olive oil or nuts improves endothelial markers involved in blood pressure control in hypertensive women. Eur. J. Nutr. 1-9. http://dx.doi. org/10.1007/s00394-015-1060-5

Strazzullo P, Ferro-Luzzi A, Siani A, Scaccini C, Sette S, Catasta G.1986. Changing the Mediterranean diet: effects on blood pressure. J. Hypertens 4, 407-412.

Tripoli E, Giammanco M, Tabacchi G, Di Majo D, Giammanco S, La Guardia M. 2005. The phenolic compounds of olive oil: structure, biological activity and beneficial effects on human health. Nutr. Res. Rev. 18, 98-112. http://dx.doi. org/10.1079/NRR200495 
Tsimikas S, Brilakis ES, Miller ER, McConnell JP, Lennon RJ, Kornman KS. 2005. Oxidized phospholipids, $\mathrm{Lp}$ (a) lipoprotein, and coronary artery disease. $N$. Engl. J. Med. 353, 46-57. http://dx.doi.org/10.1056/ NEJMoa043175

US Food and Drug Administration. Press Release P04-100. 11/2004. http://www.fda.gov/bbs/topics/news/2004/ NEW01129.htlm.

Visioli F, Galli C, Plasmati E, Viappiani S, Hernandez A, Colombo C. 2000. Olive phenol hydroxytyrosol prevents passive smoking-induced oxidative stress. Circulation 102, 2169-2171

Willett WC, Sacks F, Trichopoulou A, Drescher G, FerroLuzzi A, Helsing E. 1995. Mediterranean diet pyramid: a cultural model for healthy eating. Am. J. Clin. Nutr. 616, 1402S-1406S. http://www.euro.who.int/en/health-topics/ noncommunicable-diseases/cardiovascular-diseases $2 /$ definition-of-cardiovascular-diseases

Zern T, Fernandez M. 2005. Cardioprotective effects of dietary polyphenols. J. Nutr. 135, 2291-4. 